\title{
Intra-abdominal hypertension due to heparin - induced retroperitoneal hematoma in patients with ventricle assist devices: report of four cases and review of the literature
}

Stavros I Daliakopoulos ${ }^{1 *}$, Manja Schaedel ${ }^{1}$, Michael N Klimatsidas ${ }^{2}$, Sotirios Spiliopoulos ${ }^{1}$, Reiner Koerfer ${ }^{1}$, Gero Tenderich'

\begin{abstract}
Introduction: Elevated intra-abdominal pressure (IAP) has been identified as a cascade of pathophysiologic changes leading in end-organ failure due to decreasing compliance of the abdomen and the development of abdomen compartment syndrome (ACS). Spontaneous retroperitoneal hematoma (SRH) is a rare clinical entity seen almost exclusively in association with anticoagulation states, coagulopathies and hemodialysis; that may cause ACS among patients in the intensive care unit (ICU) and if treated inappropriately represents a high mortality rate.

Case Presentation: We report four patients (a 36-year-old Caucasian female, a 59-year-old White-Asian male, a 64-year-old Caucasian female and a 61-year-old Caucasian female) that developed an intra-abdominal hypertension due to heparin-induced retroperitoneal hematomas after implantation of ventricular assist devices because of heart failure. Three of the patients presented with dyspnea at rest, fatigue, pleura effusions in chest XR and increased heart rate although b-blocker therapy. A 36-year old female (the forth patient) presented with sudden, severe shortness of breath at rest, 10 days after an "acute bronchitis". At the time of the event in all cases international normalized ratio (INR) was $<3.5$ and partial thromboplastin time $<65 \mathrm{sec}$. The patients were treated surgically, the large hematomas were evacuated and the systemic manifestations of the syndrome were reversed.

Conclusion: Identifying patients in the ICU at risk for developing ACS with constant surveillance can lead to prevention. ACS is the natural progression of pressure-induced end-organ changes and develops if IAP is not recognized and treated in a timely manner. Failure to recognize and appropriately treat ACS is fatal while timely intervention - if indicated - is associated with improvements in organ function and patient survival. Means for surgical decision making are based on clinical indicators of adverse physiology, rather than on a single measured parameter.
\end{abstract}

\section{Background}

Ventricular assist devices (VADs) have been demonstrated to be effective in either bridging patients with end-stage heart failure to transplantation or as longterm support - destination therapy - or as a bridge to myocardial recovery resulting in substantial improvement in survival rates [1,2]. For every 1000 patients with end-stage heart failure, the implantation of a left

\footnotetext{
* Correspondence: sdaliakopoulos@hotmail.de

${ }^{1}$ Herzzentrum Essen, Herwarthstrasse 100, 45138 Essen, Germany

Full list of author information is available at the end of the article
}

ventricular assist device could prevent at least 270 deaths annually. The treatment effect is nearly four times that of beta-blockers or angiotensin-converting enzyme inhibitors (ACE inhibitors), which have been estimated to prevent 70 deaths for every 1000 patients treated who receive either type of agent $[3,4]$. The Achilles' heel of Prolonged Ventricular Assist Device Support has been right ventricular dysfunction and device-related complications, such as thromboembolism, infection, and bleeding. The latter is triggered by changes in the coagulation system [5,6] and remains the most common postoperative complication after VAD 
implantation, necessitating reoperation in up to $60 \%$ of cases irrespective of device used or indication for insertion.

Spontaneous retroperitoneal hematoma (SRH) on the other hand is a distinctive clinical entity, most commonly seen in association with patients with anticoagulation therapy, bleeding abnormalities, and haemodialysis $[7,8]$ and may represent one of the most serious and potentially lethal complications of anticoagulation therapy [9]. The large study of Sasson et al. [10] showed that patients receiving heparin as anticoagulation therapy should be carefully monitored for the development of groin pain or leg weakness because of a SRH. Monica Mourthe et al reported the only case where abdominal compartment syndrome was related to this clinical entity [11].

The World Society of Abdominal Compartment Syndrome has defined Intra-abdominal hypertension as a sustained or repeated pathologic elevation of IAP $\geq 12$ $\mathrm{mmHg}$ whereas the same society defined the Abdominal
Compartment Syndrome as a sustained IAP $>20 \mathrm{mmHg}$ associated with new organ dysfunction or failure, with signs of end-organ compromise, confirmed by alleviation of symptoms on abdominal decompression. Both of these entities compress the pulmonary parenchyma which results in an increased intrapulmonary shunt fraction.

\section{$1^{\text {st }}$ Case presentation}

The $1^{\text {st }}$ case we report is of a 36-year-old Caucasian female with severe heart failure secondary to virus induced myocarditis that required biventricular support with Thoratec PVAD $^{(\mathrm{r})}$ ventricular assist device (Thoratec Laboratories Corp, Pleasanton, CA). She was initially treated with Furosemid $\left(\operatorname{Lasix}^{(\mathrm{r})}\right) 500 \mathrm{mg} / 50 \mathrm{ml} \mathrm{NaCl}$ with a rate of 5-10 $\mathrm{mg} / \mathrm{h}, \mathrm{ACE}$ inhibitors, and dobutamin ${ }^{(\mathrm{r})} 250 \mathrm{mg} / 50 \mathrm{ml}$ with a rate of $10 \mu \mathrm{g} / \mathrm{KG} \mathrm{BW} / \mathrm{min}$. Despite maximal medical treatment, including levosimendan $\left(\operatorname{Simdax}^{(\mathrm{r})}\right) 25 \mathrm{mg} /$ $500 \mathrm{ml} \mathrm{G5 \%}$ with a rate of $0.1 \mu \mathrm{g} / \mathrm{KG} \mathrm{BW} / \mathrm{min}$, her clinical and hemodynamic status deteriorated 36 hours later with hypotension, cardiac index $(\mathrm{CI})$ of $1.60 \mathrm{~L} / \mathrm{min} / \mathrm{m}^{2}$ and

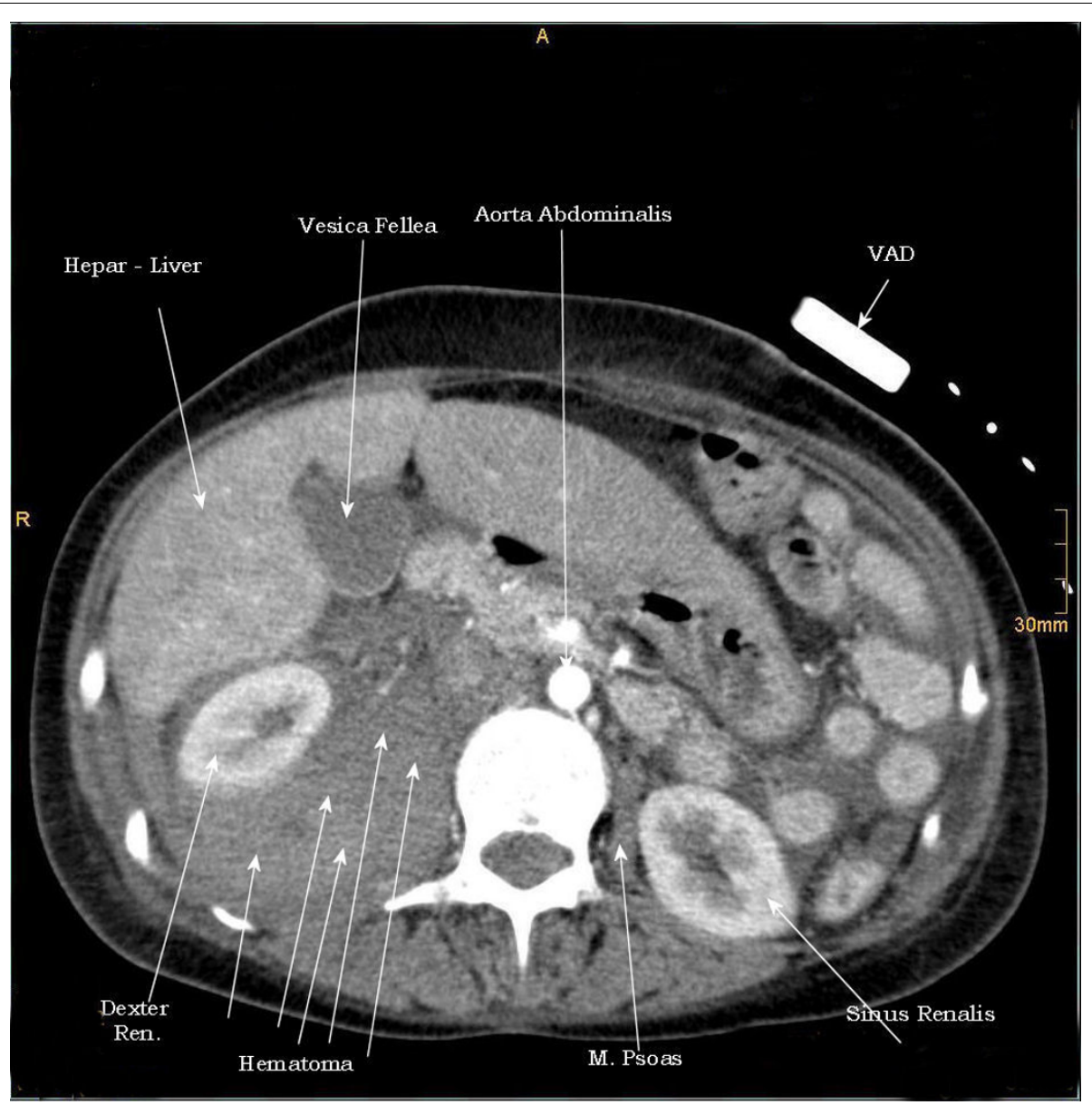

Figure $11^{\text {st }}$ case. CT - axial plan demonstrating a retroperitoneal hematoma adherent to the right psoas muscle, shifting the right renal lateral. 
cardiogenic shock, with threatening multiple organ failure. The patient was evaluated and accepted for ventricular assist device implantation.

Postoperatively, after spending 128 hours in the ICU and while in mechanical ventilation, her liver and kidney function promptly recovered, the inotropic agents were reduced, and the patient remained clinically stable under dobutamin \& dopamine and heparin IV. Heparin therapy was monitored three times per day, using the partial thromboplastin time (aPTT) and the dose was adjusted to attain the target $50-60 \mathrm{sec}$.

On the $7^{\text {th }}$ ICU-day the patient developed a tense, distended abdomen and became oliguric. Pulmonary vascular resistance was 305 dyn $\times \mathrm{sec} / \mathrm{cm}^{5}$. Abdominal ultrasound revealed an empty bladder with a urinary catheter in situ and kidneys of normal size. Despite to an adequate mean arterial pressure $(65 \mathrm{~mm} \mathrm{Hg})$ and passage of a nasogastric tube to decompress the stomach, oliguria persisted. Intraabdominal pressure (IAP) was measured via a urinary catheter and was shown to be $27 \mathrm{~mm} \mathrm{Hg}$, which confirmed abdominal compartment syndrome
(ACS) [12]. CT of the abdomen and pelvis showed a large retroperitoneal hematoma (Figure 1). The patient was initially treated with transfusion of 8 units of packed red cells (PRC) and 4 units of fresh frozen plasma (FFP). Despite adequate fluid and blood product resuscitation the patient remained unstable so that the large retroperitoneal hematoma had to be surgically removed on the $8^{\text {th }}$ ICU-day. The patient remained in the ICU for 47 days.

\section{$2^{\text {nd }}$ Case presentation}

A 59-year-old White-Asian male was admitted to hospital and required support with Heart Mate II Thoratec $^{(r)}$ LVAS because of terminal heart insufficient due to idiopathic dilated cardiomyopathy. On the $6^{\text {th }}$ ICUday hemodynamic indicators included elevated heart rate $(\mathrm{HF}>140 \mathrm{~b} / \mathrm{min}$ ), hypotension (Systolic/Diastolic BP 60/40 mm Hg), elevated Pulmonary Artery Wedge Pressure $(27 \mathrm{mmHg}$ ) and Central Venous Pressure (CVP $16 \mathrm{mmHg}$ ) with elevated Systemic - SVR: 1500 dyn $\times \mathrm{sec} / \mathrm{cm}^{5}$ and Pulmonary - PVR: $345 \mathrm{dyn} \times \mathrm{sec} /$ $\mathrm{cm}^{5}$ Vascular Resistance made the patient's mechanical

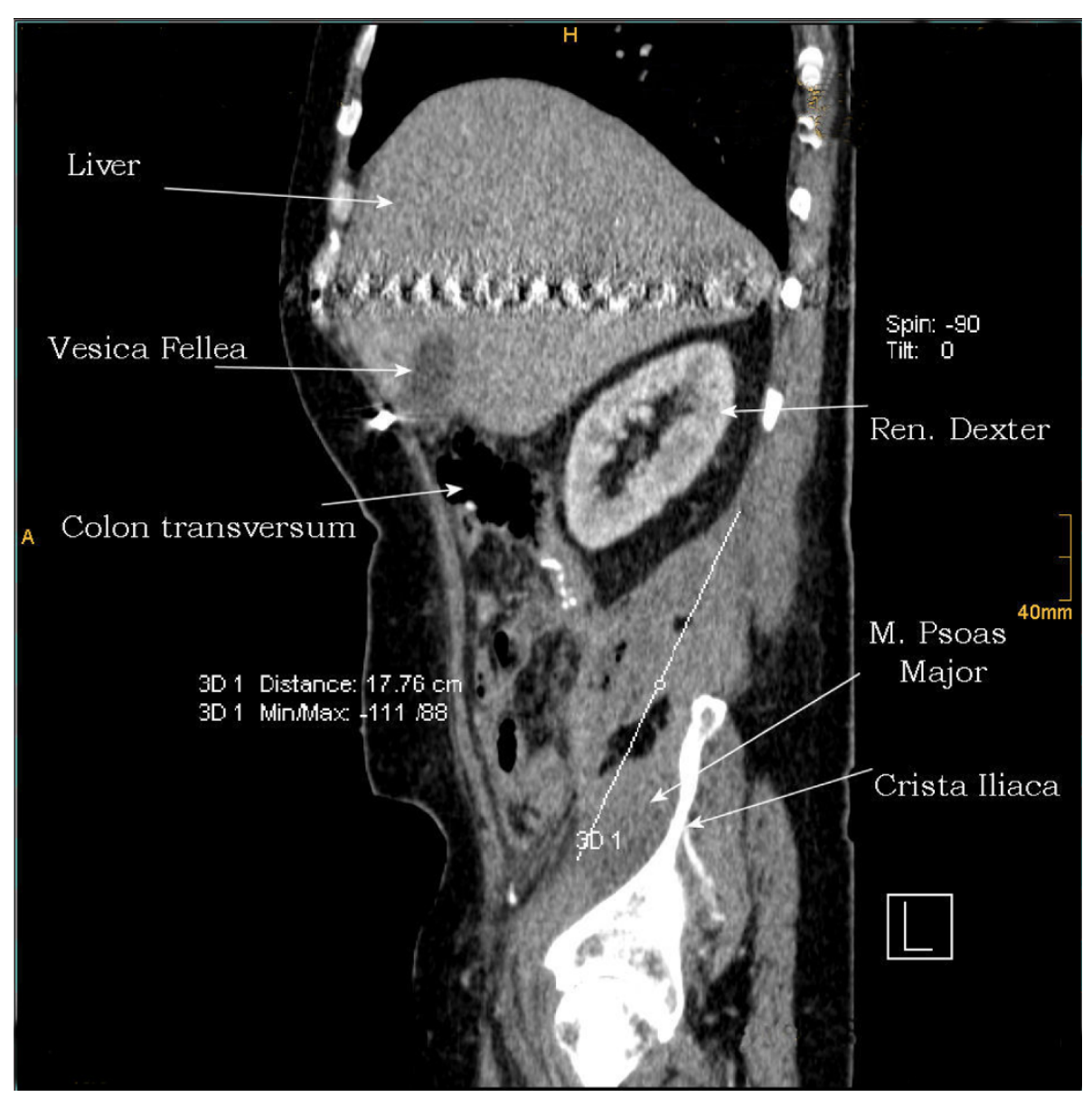

Figure $22^{\text {nd }}$ case. CT - sagittal plan of a large retroperitoneal hematoma $-17.76 \mathrm{~cm}$. 
ventilation difficult, requiring high peak inflating pressures $\left(\mathrm{P}_{\max } 34 \mathrm{mmHg}\right.$ and high positive expiratory end-pressure (PEEP > 10) in order to maintain adequate oxygenation. During the next hours the patient became anuric with IAP of $22 \mathrm{mmHg}$. CT revealed a $17,76 \mathrm{~cm}$ (Figure 2, 3) retroperitoneal hematoma that was surgically removed. The retroperitoneum had to be packed and a re-exploration was necessary $72 \mathrm{~h}$ later before the final closure. The patient was discharged from the ICU on $56^{\text {th }}$ postoperative day (after LVAD implantation).

\section{$3^{\text {rd }}$ Case presentation}

A 64-year-old Caucasian female on $10^{\text {th }}$ postoperative day after Heart Mate II Thoratec ${ }^{(\mathrm{r})}$ LVAS became anuric while IAP was $23 \mathrm{mmHg}$. CT revealed a $30 \mathrm{~cm}$ retroperitoneal hematoma that was surgically removed (Figure $4,5,6$ ). The patient died on the $89^{\text {th }}$ postoperative day in the ICU because of multiple organs insufficiency.

\section{$4^{\text {th }}$ Case presentation}

A 61-year-old Caucasian female required mechanical ventilation and dialysis due to respiratory distress syndrome and anuria on $13^{\text {th }}$ postoperative day after Heart Mate II Thoratec ${ }^{(\mathrm{r})}$ LVAS. CT on $15^{\text {th }}$ postoperative day revealed a large retroperitoneal hematoma that was surgically removed (Figure 7 ). The patient remained in the ICU for 63 days.

\section{Discussion}

Postoperative hemorrhage is common among patients with VADs and many of them have risk factors predisposing to hemorrhage. Risk factors for significant hemorrhage include coagulopathy due to hepatic congestion associated with severe heart failure, compromised nutritional status, preoperative anticoagulation therapies, and previous cardiac surgery [13]. Although extensive bleeding usually occurs into the mediastinum or pericardial space, VADs can have other complications not confined to the chest. Hemolysis and resulting

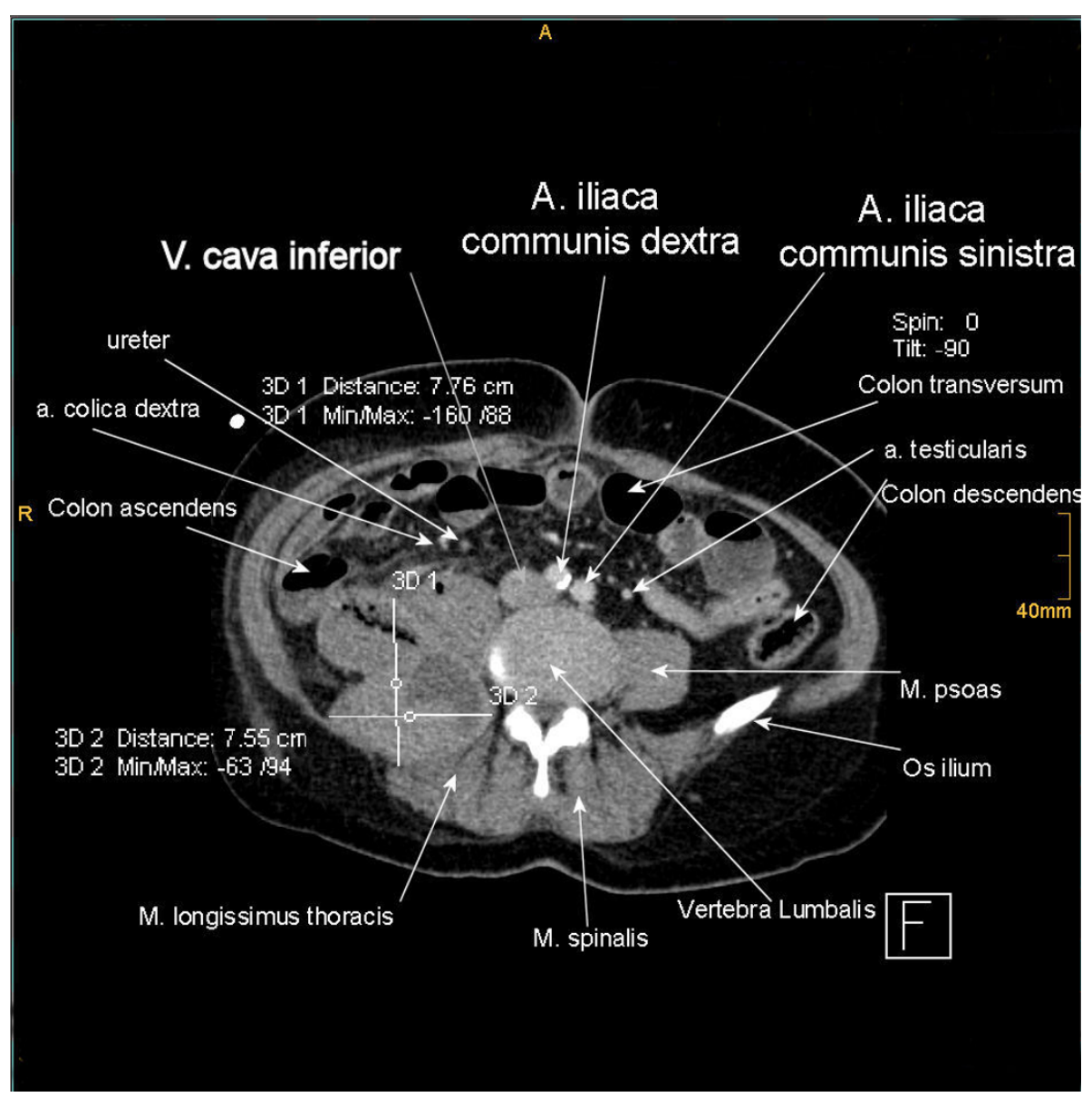

Figure $32^{\text {nd }}$ case. CT - axial plan of the hematoma shifting the right ureter to the middle line. 


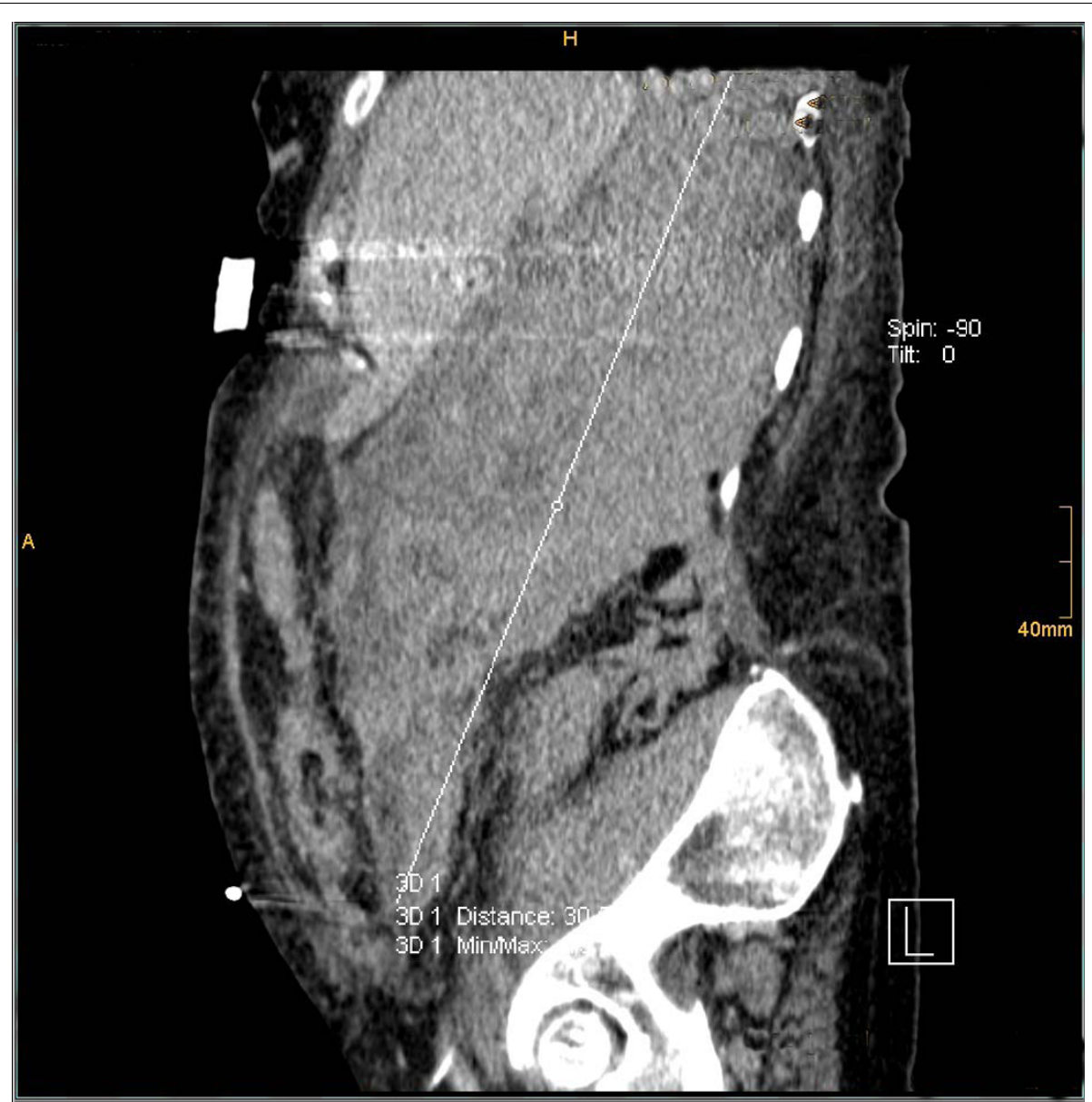

Figure $43^{\text {rd }}$ case. $C T$ - sagittal plan demonstrating a $30 \mathrm{~cm}$ hematoma.

biliary complications are common and according to John R. [14] and Kamdar F. [15] axial flow devices (Heart Mate II to our cases) seem to be associated with higher rate of gastrointestinal bleeding, ventricular arrhythmias and intracranial hemorrhage.

All of our patients developed IAH as a consequence of large retroperitoneal hematoma and reduced intraabdominal volume. This was inferred by changes in the patient's hepatic transaminases and was manifested by oliguria, raised abdominal pressure and inadequate oxygenation result in hypercapnia and acidosis requiring high PEEP and peak ventilator pressures, which exacerbate the hemodynamic abnormalities.

Retroperitoneal hematoma among patients in the ICU is a well-recognized but relative rare condition with an incidence of $0.1 \%$, although has been reported at 0.6 $6.6 \%$ of patients undergoing therapeutic anticoagulation $[16,17]$. Warfarin, unfractioned and low-molecular heparin have all been implicated $[18,9]$.

All the patients in our cases before operation and in order to receive a $\mathrm{LAD}$ or a $\mathrm{Bi}-\mathrm{VAD}$ they were examined for Heparin Induced Thrombocytopenia (ELISA \& HIPAA). In all cases the HIT test was negative. After the implantation of the assist device the number of platelets was reduced but the post- operation labor examination didn't provide any signs of HIT.

Appendix 1 demonstrates the 4 Grades of IAH according to the World Society of the Abdominal Compartment Syndrome. The mortality rate in patients with IAH and ACS varies from 29 to $62 \%$ and is usually due to multiple organ failure and sepsis [19-21]. A diverse range of associated conditions may lead to from $\mathrm{IAH}$ to ACS requiring aggressive fluid resuscitation (Appendix 2).

The earliest manifestation of ACS is reported by Eddy et al. [22] to be the pulmonary dysfunction. IAP is transmitted to the thorax both directly and through cephalad deviation of the diaphragm. This significantly increases intrathoracic pressure resulting in extrinsic compression of the pulmonary parenchyma and development of pulmonary dysfunction [23,24]. Increased intrapleural pressures resulting from transmitted 


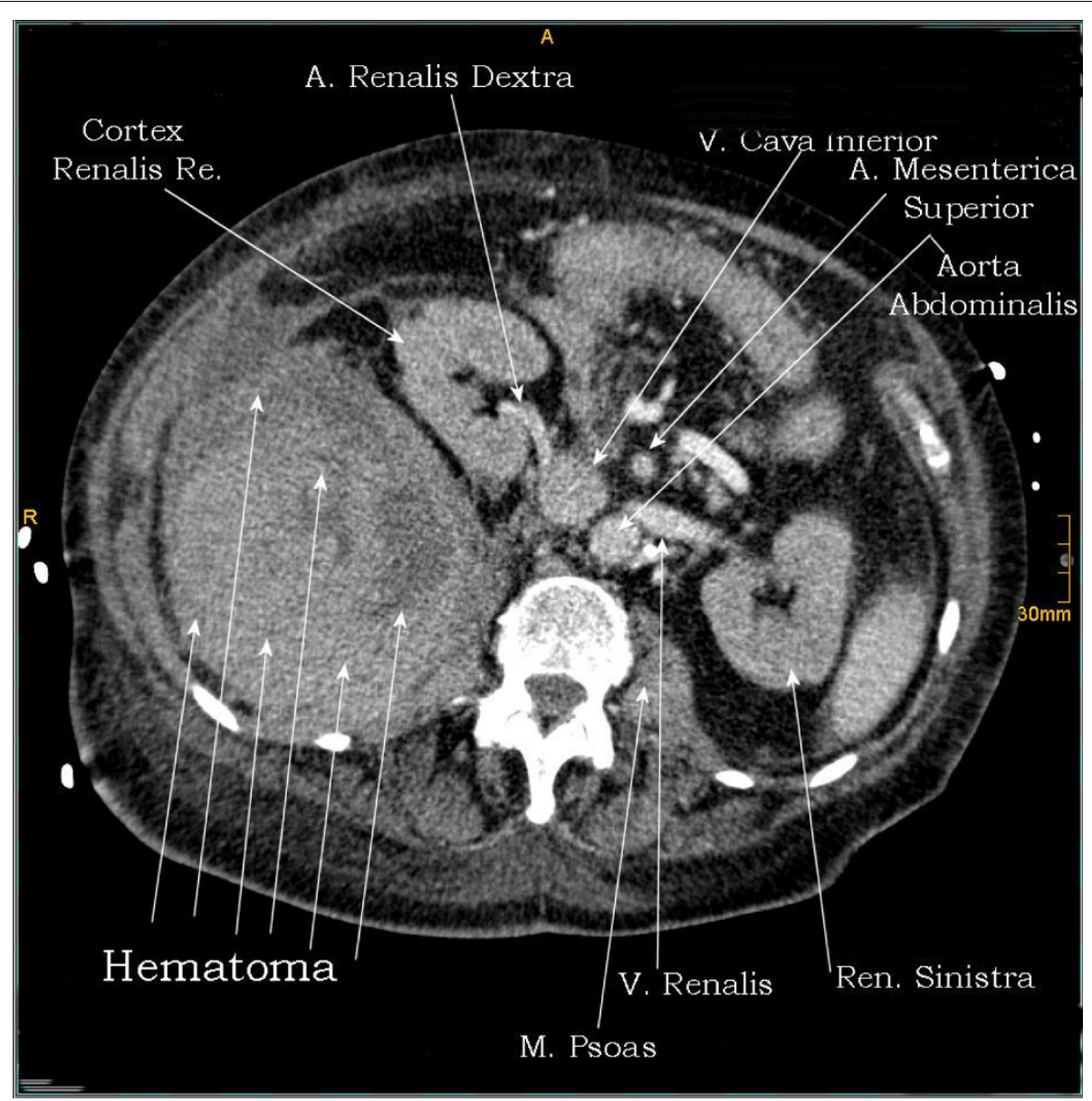

Figure $53^{\text {rd }}$ case. $C T$ - axial plan of a huge hematoma shifting the whole right renal to the middle line.

intra-abdominal forces produce elevations in measured hemodynamic parameters including CVP and PAWP resulting in false LVAD or PVAD settings. In our series of cases we noted that accurate prediction of enddiastolic filling pressures was no longer reliable to be made from PAWP equations but via transoesophageal echocardiography. Significant hemodynamic changes have been demonstrated with IAP above $20 \mathrm{mmHg}$ [25].

Oliguria or even anuria develops despite measured normal or mildly elevated CPV and PAWP due to IAHinduced reductions in renal blood flow and function $[26,27]$. Because of IAP renal vein and renal vascular resistance are both significant elevated leading to impaired glomerular and tubular renal function and reduction in urinary output $[23,26,27]$. Nevertheless interesting is the fact that renal failure in the absence of pulmonary dysfunction is not likely to be the result of IAH [22].

Because many of the effects of ACS are clinically indistinguishable from those of other common entities related to critically ill patients, it is probable that the influence of an elevated IAP is not infrequently missed in a patient with multifactorial complications. As a result, clinicians must possess a high index of suspicion and monitor IAP frequently. Contemporary measurement of the IAP outside of the laboratory is accomplished by a variety of means. These include direct measurement of IAP by means of an intra-peritoneal catheter, as is done during laparoscopy. Bedside measurement of IAP has been accomplished by transduction of pressures from indwelling femoral vein, rectal, gastric and urinary bladder catheters. The latter method is used in our institution and is possible by measuring intracystic pressure (ICP) as a reflection of IAP using a Foley catheter [28-30] although large series of human studies correlating ICP and IAP are lacking to date [31]. Continuous Intra-cystic pressure measure was used to determine the IAP indirectly at the era of the first signs of IAH.

Chest radiography can be used to evaluate gross positioning of the pump and the inflow and outflow 


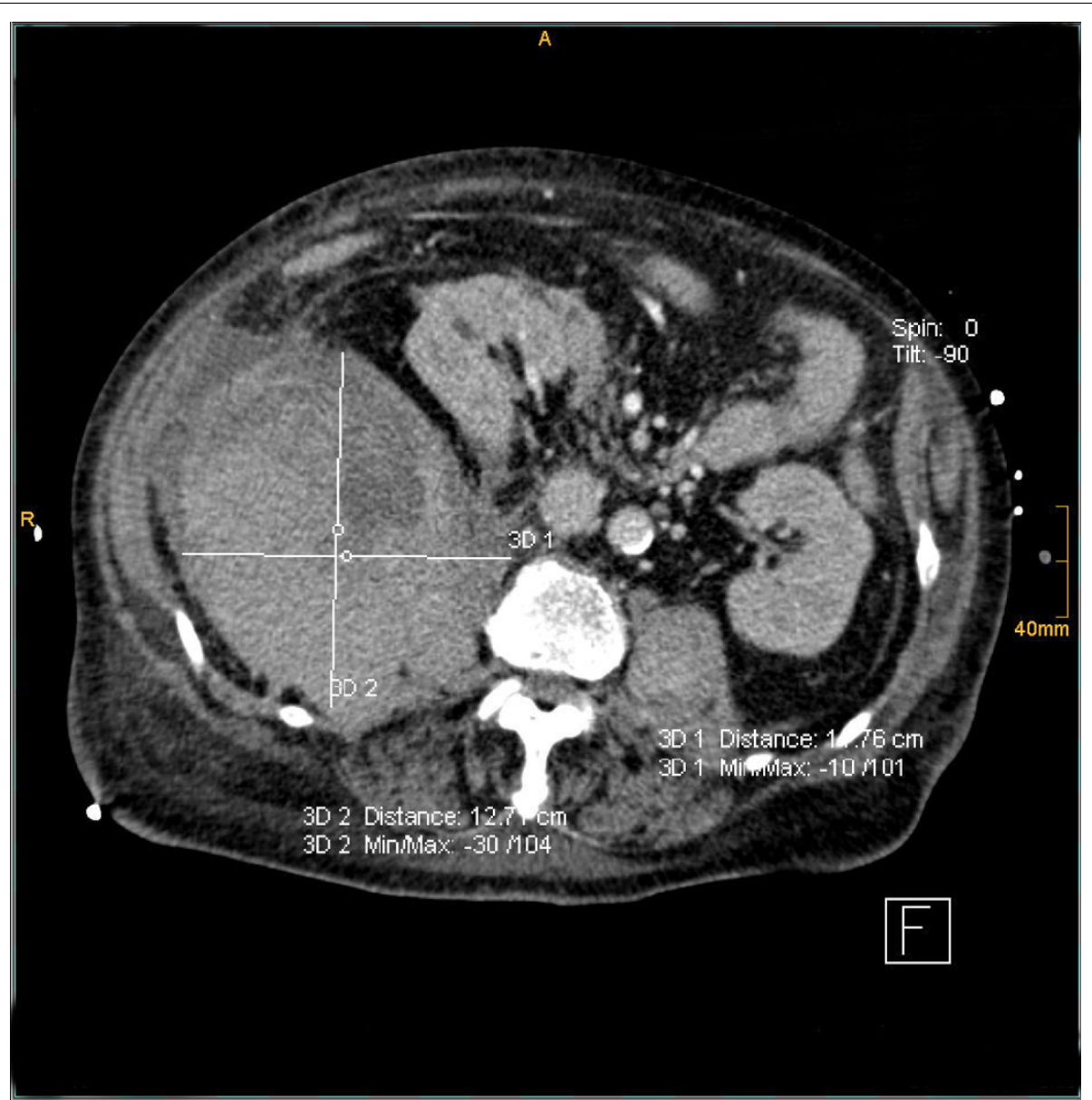

Figure $63^{\text {rd }}$ case. CT - axial plan of the hematoma.

cannulas or may show elevated hemidiaphragms with loss of lung volume but these findings seem to be difficult to identify in patients with VADs. These changes have been demonstrated with IAP above $15 \mathrm{mmHg}$ [25]. Transoesophageal echocardiography was routinely employed to all of our patients during the intraoperative and perioperative periods to evaluate thrombus formation, pump flow, mechanical complications and ventricular filling and uploading but CT detected in all cases the problem. Common CT features included extrinsic compression of the inferior vena cava (IVC), positive round belly sign and an anteroposterior-to-transverse abdominal ratio of more than 80 [32].

The usual treatment of ACS by decompression of the abdomen, often by laparotomy, in those with moderately elevated intra-abdominal pressure is growing in vogue $[12,33]$, although conservative treatment is comprised of supportive therapy and abdominal decompression with nasogastric tube and flatus tube.

In our cases the indication of open surgery ACS was complicated of the presence of the large retroperitoneal hematoma. We didn't proceed to a decompressive laparotomy because all of the hematomas were so tense that the possibility of anterior eruption after abdominal pressure released was high. We preferred to remove the large hematoma in order to avoid this phenomenon and in one case we had to pack and re-explore the retroperitoneum because of diffuse bleeding.

Before operating hematological values were restored and coagulopathy cascade was corrected by replacement of coagulation factors. In all patients from the second postoperative day (after LVAD or PVAD implantation) and till weaning from mechanical ventilation (MV) unfractioned heparin was used in continuous $24 \mathrm{~h}$ pump perfusion without discharge aiming a target aPTT 50-60 sec. After weaning from MV and two days after the last drainage was removed all of the patients received additional anticoagulation therapy, initially phenprocoumon $3 \mathrm{mg}$ (Marcumar ${ }^{(\mathrm{r})}$ ) aiming a target INR 2.5-3.5 and finally acetylsalicylsäure $\left(\mathrm{ASS}^{(\mathrm{r})} 100\right.$ $\mathrm{mg} /$ day). Marcumar ${ }^{(\mathrm{r})}$ and $\mathrm{ASS}^{(\mathrm{r})}$ were not discontinued after hospital discharge. 


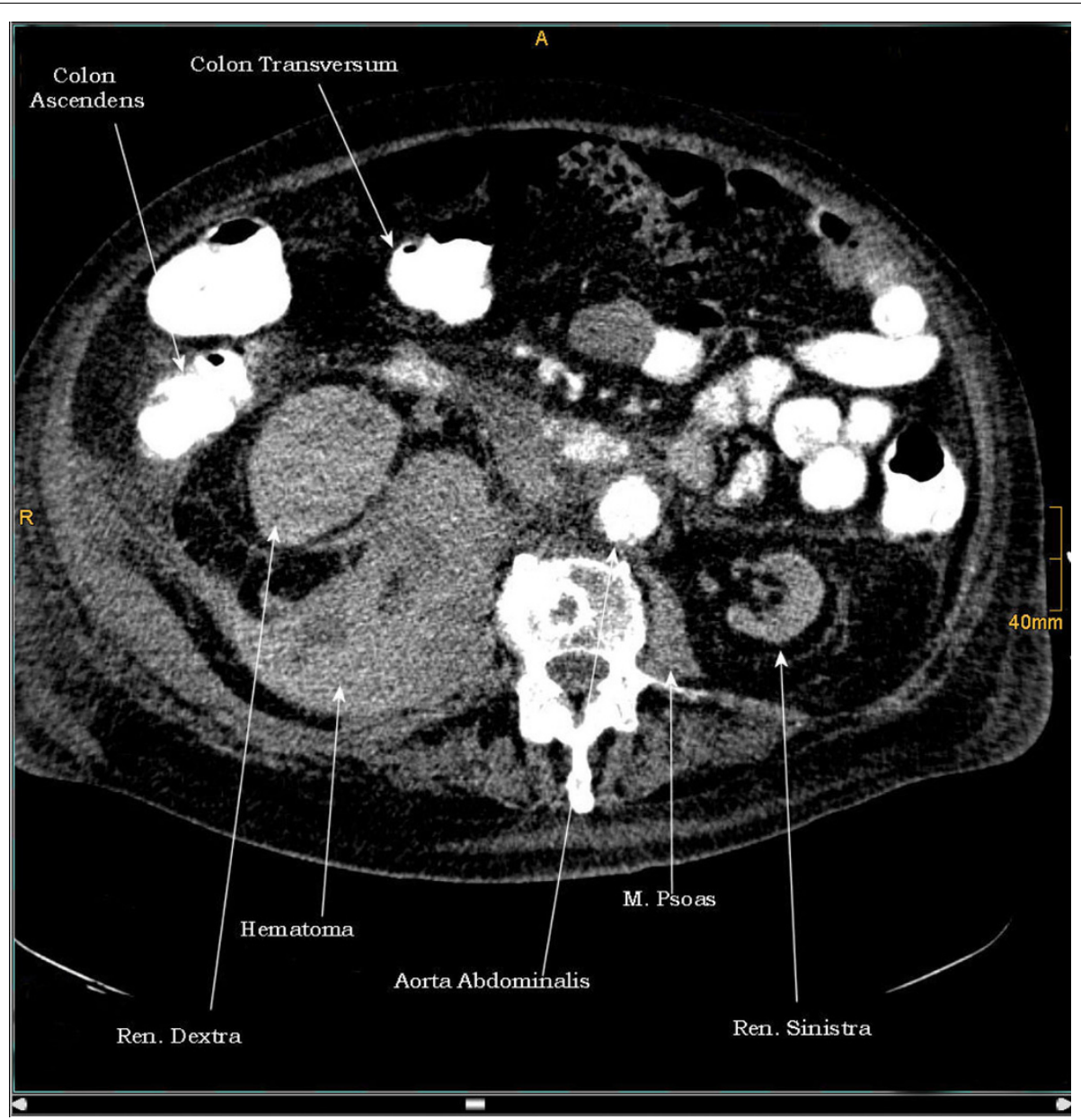

Figure $74^{\text {th }}$ case. $C T$ - axial plan of the hematoma.

To avoid a reperfusion syndrome from the release of acid and metabolites from reperfused tissues after the abdomen decompression [34,35]. we used in all cases a two liter solution consisting of $0.45 \%$ Normal Saline with $50 \mathrm{gr}$ of Mannitol and $50 \mathrm{mEq}$ of Sodium Bicarbonate [36].

\section{Conclusion}

IAH has a significant role in contributing to the early multiple organ dysfunction syndrome (MODS). The presentation is varied and may be vague and diagnosis is often delayed. The patients who have retroperitoneal hematoma as cause of the IAH often do not have any obvious clinical signs. Relative hypotension and mild tachycardia are most of the time present. Any abnormal and sudden increase in the volume of any component of the intra-peritoneal or extra-peritoneal spaces can cause Intra-abdominal Hypertension. When associated with organ dysfunction (elevated airway pressure, cardiac output reduction and oliguria) it meets the criteria for Abdomen Compartment Syndrome. Treatment consists of prompt surgical decompression, volemic resuscitation and any further strategy is based on recognition of resultant organ dysfunction.

Our report finally indicates that ACS can occur outside the typical setting of abdominal surgery or trauma, decompressive laparotomy is not always the gold standard and patients with VADs may be at high risk for postoperative IAH and ACS.

\section{Consent}

Written informed consent was obtained from our patients for publication of this case report and any accompanying images. A copy of the written consent is available for review by the Editor-in-Chief of this journal.

\section{Appendices}

Appendix 1

IAH Grading System according to the WSACS

Grade I: IAP $12-15 \mathrm{mmHg}$

Grade II: IAP $16-20 \mathrm{mmHg}$

Grade III: IAP 21-25 mmHg

Grade IV: IAP > $25 \mathrm{mmHg}$ 


\section{Appendix 2}

Risk factors responsible for IAH/ACS $\mathrm{According}_{\text {to the }}$ WSACS

Mechanical ventilation

Acidosis $(\mathrm{pH}<7,2)$

Polytransfusion ( $>10 \mathrm{U}$ Packed Red Blood/24 h)

Hypothermia (core temperature $<33^{\circ} \mathrm{C}$ )

Sepsis

Bacteremia

Intra-abdominal infection/abscess

Pneumonia

Peritoneal Dialysis

Abdominal surgery, especially with fascial closures

Massive fluid resuscitation ( $>5$ lt colloid or crystalloid/

$24 \mathrm{~h})$

Gastroparesis - gastric distention - ileus

Major burns

Major trauma

Prone positioning

Massive incisional hernia repair

Damage control laparotomy

Laparoscopy with excessive inflation pressures

High Body Mass Index $\left(>30 \mathrm{Kg} / \mathrm{m}^{2}\right)$

Coagulopathy

Liver dysfunction/cirrhosis with ascites

Hemoperitoneum/pneumoperitoneum

Acute pancreatitis

Peritonitis

Intra-abdominal or retroperitoneal tumors

\section{Author details}

${ }^{1}$ Herzzentrum Essen, Herwarthstrasse 100, 45138 Essen, Germany. ${ }^{2} 424$

Military Hospital of Thessaloniki, Thoracic Surgery Department, 56429

Thessaloniki, Greece.

\section{Authors' contributions}

SID participated in the sequence alignment, designing the case report and drafting the manuscript. MS participated in the design of the case report. MNK participated in the design of the case report. SS participated in the design and culled relevant information. RK participated in the design of the case report. GT coordinated the preparation of the case report and designed the whole manuscript. All authors read and approved the final manuscript.

\section{Competing interests}

The authors declare that they have no competing interests.

Received: 12 July 2010 Accepted: 10 November 2010

Published: 10 November 2010

\section{References}

1. Peterze B, Lonn U, Jansson K, Rutberg H, Casimir-Ahn H, Nylander E: Long term follow-up of patients treated with an implantable left ventricular assist device as an extended bridge to heart transplantation. $J$ Heart Lung Transplant 2002, 21:604-7.

2. Pennington DG, McBride LR, Peigh PS, Miller LW, Swartz MT: Eight years' experience with bridging to cardiac transplantation. J Thorac Cardiovasc Surg 1994, 107:472-81.

3. Kjekshus J, Swedberg K, Snapinn S: Effects of enalapril on long-term mortality in severe congestive heart failure. Am J Cardiol 1992, 69:103-7.
4. Packer M, Coats AJ, Fowler MB, Katus HA, Krum H, Mohacsi P, Rouleau JL, Tendera M, Castaigne A, Roecker EB, Schultz MK, Staiger C, Curtin E, DeMets DL, for the Carvedilol Prospective Randomized Cumulative Survival Study Group: Effect of carvedilol on survival in severe chronic heart failure. N Engl J Med 2001, 344:1651-8.

5. Livingston ER, Fisher CA, Bibidakis EJ, Pathak AS, Todd BA, Furukawa S, McClurken JB, Addonizio VP, Jeevanandam V: Increased activation of the coagulation and fibrinolytic systems lead to hemorrhagic complications during left ventricular assist implantation. Circulation 1996, 94(Suppl II):227-34.

6. Himmelreich $G$, Ullmann $H$, Riess $H$, Rosch R, Loebe M, Schiessler A, Hetzer R: Pathophysiologic role of contact activation in bleeding followed by thromboembolic complications after implantation of a ventricularassist device. ASAIO J 1995, 41:M790-4.

7. Bhasin HK, Dana CL: Spontaneous retroperitoneal hemorrhage in chronically hemodialyzed patients. Nephron 1978, 22:322-7.

8. Fernadez-Palazzi F, Hernandez SR, De Bosch NB, De Saez AR: Hematomas within the iliopsoas muscles in hemophilic patients: the Latin American experience. Clin Orthop Relat Res 1996, 328:19-24.

9. Stavros IDaliakopoulos, Andreas Bairaktaris, Dimitrios Papadimitriou, Perikles Pappas: Gigantic retroperitoneal hematoma as a complication of anticoagulation therapy with heparin in therapeutic doses: a case report. Journal of Medical Case Reports 2008, 2:162.

10. Sasson Z, Mangat I, Peckham KA: Spontaneous iliopsoas hematoma in patients with unstable coronary syndromes receiving intravenous heparin in therapeutic doses. Can J Cardiol 1996, 12:490-494.

11. Mourthe de Alvim Andrade Monica, Batista Pimenta Marcelo, de Freitas Belezia Bruno, Lodi Xavier Rafael, Motte Neiva Augusto: Abdominal compartment syndrome due to warfarin-related retroperitoneal hematoma. Clinics 2007, 62(6):781-4.

12. Biffl WL, Moore EE, Burch JM, Offner PJ, Franciose RJ, Johnson JL: Secondary abdominal compartment syndrome is a highly lethal event. Am J Surg 2001, 182(6):645-8.

13. Piccione $W$ Jr: Left ventricular assist device implantation: short and longterm surgical complications. J Heart Lung Transplant 2000, 19(8 suppl): S89-S94.

14. John R: Current axial-flow devices: the HeartMate II and Jarvik 2000 left ventricular assist devices. Semin Thorac Cardiovasc Surg 2008, 20(3):264-272.

15. Kamdar F, Boyle A, Liao K, Colvin-Adams M, Joyce L, John R: Effects of centrifugal, axial, and pulsatile left ventricular assist device support on end-organ function in heart failure patients. J Heart Lung Transplant 2009, 28(4):352-359.

16. Forfar JC: A 7-year analysis of haemorrhage in patients on long-term anticoagulant treatment. Br Heart J 1979, 42:128-32.

17. Estivil Palleja X, Domingo P, Fontcuberta J, Felez J: Spontaneous retroperitoneal hemorrhage during oral anticoagulant therapy. Arch Inter Med 1985, 145:1531-4.

18. Ernits M, Mohan PS, Fares LG II, Hardy H III: A retroperitoneal bleed induced by enoxaparin therapy. Am Surg 2005, 71:430-3.

19. Hunter JD, Damiani Z: Intra-abdominal Hypertension and the abdominal compartment syndrome. Anaesthesia 2004, 59:899-907.

20. Moore AF, Hargest R, Martin M, Delicata RJ: Intra-abdominal hypertension and the compartment syndrome. Br J Surg 2004, 91:1102-1110.

21. Stagnitti F, Calderale SM, Priore F, Ribaldi S, Tiberi R, De Pascalis M, et al: Abdominal compartment syndrome: pathophysiologic and clinic remarks. G Chir 2004, 25:335-342.

22. Eddy V, Nunn C, Morris JA: Abdominal compartment syndrome. Surg Clin North Am 1997, 77:801-811.

23. Bloomfield GL, Blocher CR, Fakhry IF, Sica DA, Sugerman HJ: Elevated intraabdominal pressure increases plasma rennin activity and aldosterone levels. J Trauma 1997, 42:997-1004.

24. Simon RJ, Friedlander MH, Ivatury RR, DiRaimo R, Machiedo GW: Hemorrhage lowers the threshold for intra-abdominal hypertensioninduced pulmonary dysfunction. J Trauma 1997, 42:398-403.

25. Ridings PC, Bloomfield GL, Blocher CR, Sugerman HJ: Cardiopulmonary effects of raised intra-abdominal pressure before and after intravascular volume expansion. J Trauma 1995, 39(6):1071-5.

26. Iberti TJ, Lieber CE, Benjamin E: Determination of intra-abdominal pressure using a transurethral bladder catheter: clinical validation of the technique. Anesthesiology 1989, 70:47-50. 
27. Cade R, Wagemaker H, Vogel S, Mars D, Hood-Lewis D, Privette M, Peterson J, Schlein E, Hawkins R, Raulerson D: Hepatorenal syndrome. Studies of the effect of vascular volume and intraperitoneal pressure on renal and hepatic function. Am J Med 1987, 82:427-438.

28. Harman PK, Kron IL, McLachlan HD, Freedlender AE, Nolan SP: Elevated intra-abdominal pressure and renal function. Ann Surg 1982, 196:594-597.

29. Kron IL, Harman PK, Nolan SP: The measurement of intra-abdominal pressure as a criterion for abdominal re-exploration. Ann Surg 1984, 199:28-30.

30. Iberti TJ, Kelly KM, Gentili DR, Hirsch S, Benjamin E: A simple technique to accurately determine intra-abdominal pressure. Crit Care Med 1987, 15:1140-1142.

31. Johna S, Taylor E, Brown C, Zimmerman G: Abdominal compartment syndrome: does intra-cystic pressure reflect actual intra-abdominal pressure? A prospective study in surgical patients. Critical Care 1999, 3:135-138.

32. Pickhardt PJ, Shimony JS, Heiken JP, Buchman TG, Fisher AJ: The abdominal compartment syndrome: CT findings. Am J R 1999, 173:575.

33. Mayberry JC: Prevention of abdominal compartment syndrome. The Lancet 999 354:1749 50.

34. Schein M, Wittmann DH, Aprahamian CC, Condon RE: The abdominal compartment syndrome: the physiological and clinical consequences of elevated intra-abdominal pressure. J Am Coll Surg 1995, 180:745-53.

35. Morris JA, Eddy VA, Blinman TA, Rutherford EJ, Sharp KW: The staged celiotomy for trauma Issues in unpacking and reconstruction. Ann Surg 1993, 217:576-86.

36. Priluck IA, Blodgett DW: The effects of increased intra-abdominal pressure on the eyes. Nebr Med J 1996, 81:8-9.

doi:10.1186/1749-8090-5-108

Cite this article as: Daliakopoulos et al: Intra-abdominal hypertension due to heparin - induced retroperitoneal hematoma in patients with ventricle assist devices: report of four cases and review of the literature. Journal of Cardiothoracic Surgery 2010 5:108.

\section{Submit your next manuscript to BioMed Central and take full advantage of:}

- Convenient online submission

- Thorough peer review

- No space constraints or color figure charges

- Immediate publication on acceptance

- Inclusion in PubMed, CAS, Scopus and Google Scholar

- Research which is freely available for redistribution

Submit your manuscript at www.biomedcentral.com/submit
Biomed Central 